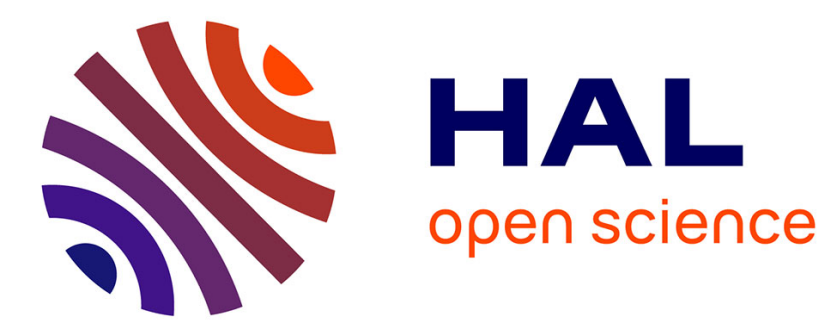

\title{
Full-field strain measurements in textile deformability studies
}

Stepan V. Lomov, Philippe Boisse, Emmanuel de Luycker, Fabrice Morestin, Kristof Vanclooster, Dirk Vandepitte, Ignass Verpoest, An Willems

\section{- To cite this version:}

Stepan V. Lomov, Philippe Boisse, Emmanuel de Luycker, Fabrice Morestin, Kristof Vanclooster, et al.. Full-field strain measurements in textile deformability studies. Composites Part A: Applied Science and Manufacturing, 2008, 39 (8), pp.1232-1244. 10.1016/j.compositesa.2007.09.014 . hal-01657911

\section{HAL Id: hal-01657911 \\ https://hal.science/hal-01657911}

Submitted on 7 Dec 2017

HAL is a multi-disciplinary open access archive for the deposit and dissemination of scientific research documents, whether they are published or not. The documents may come from teaching and research institutions in France or abroad, or from public or private research centers.
L'archive ouverte pluridisciplinaire HAL, est destinée au dépôt et à la diffusion de documents scientifiques de niveau recherche, publiés ou non, émanant des établissements d'enseignement et de recherche français ou étrangers, des laboratoires publics ou privés. 


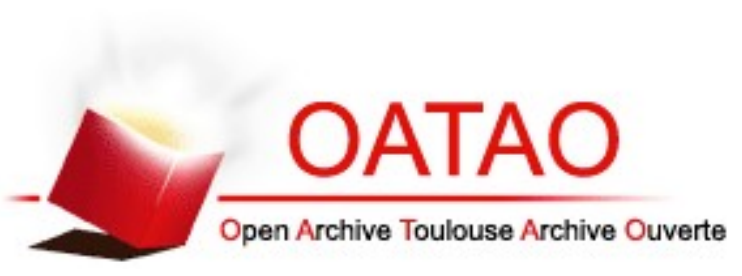

\section{Open Archive Toulouse Archive Ouverte (OATAO)}

OATAO is an open access repository that collects the work of Toulouse researchers and makes it freely available over the web where possible.

This is an author-deposited version published in: http://oatao.univ-toulouse.fr/ Eprints ID: 18485

To link to this article:

DOI:10.1016/j.compositesa.2007.09.014

URL:https://doi.org/10.1016/j.compositesa.2007.09.014

\section{To cite this version:}

Lomov, Stepan V. and Boisse, Philippe and De Luycker, Emmanuel and Morestin, Fabrice and Vanclooster, Kristof and Vandepitte, Dirk and Verpoest, Ignass and Willems, An Full-field strain measurements in textile deformability studies. (2008) Composites Part A: Applied Science and Manufacturing, vol. 39 ( $\mathrm{n}^{\circ} 8$ ). pp. 1232-1244. ISSN 1359-835X

Any correspondence concerning this service should be sent to the repository administrator: staff-oatao@,listes-diff.inp-toulouse.fr 


\title{
Full-field strain measurements in textile deformability studies
}

\author{
S.V. Lomov ${ }^{\mathrm{a}, *}$, Ph. Boisse ${ }^{\mathrm{c}}$, E. Deluycker ${ }^{\mathrm{c}}$, F. Morestin ${ }^{\mathrm{c}}, \mathrm{K}$. Vanclooster ${ }^{\mathrm{a}}$, D. Vandepitte ${ }^{\mathrm{b}}$, \\ I. Verpoest ${ }^{a}$, A. Willems ${ }^{b}$ \\ ${ }^{a}$ Department of Metallurgy and Materials Engineering, Katholieke Universiteit Leuven, Kasteelpark Arenberg, 44, B-3001 Leuven, Belgium \\ ${ }^{\mathrm{b}}$ Mechanical Engineering Department, Katholieke Universiteit Leuven, Celestijnenlaan 300B, 3001 Leuven, Belgium \\ ${ }^{\mathrm{c}}$ Laboratoire de Mécanique des Contacts et des Structures, INSA Lyon, France
}

\begin{abstract}
Full-field strain measurements are applied in studies of textile deformability during composite processing: (1) in testing of shear and tensile deformations of textiles (picture frame, bias and biaxial extension test) as an "optical extensometer", allowing accurate assessment of the sample deformation, which may differ significantly from the deformation applied by the testing device; (2) to study mechanisms of the textile deformation on the scale of the textile unit cell and of the individual yarns (meso- and micro-scale full-field strain measurements); (3) to measure the 3D-deformed shape and the distribution of local deformations (e.g., shear angles) of a textile reinforcement after draping, providing input data for the validation of material drape models and for the prediction of the consolidated part performance via structural finite element analysis. This paper discusses these three applications of the full-field strain measurements, providing examples of studies of deformability of woven (glass, glass/PP) and non-crimp (carbon) textile reinforcements. The authors conclude that optical full-field strain techniques are the preferable (sometimes the only) way of assuring correct deformation measurements during tensile or shear tests of textile.
\end{abstract}

Keywords: A. Fabrics/textiles; B. Mechanical properties; D. Mechanical testing; E. Forming

\section{Introduction}

The deformability of textile fabrics and its dependency on the fabric structure is an important issue for technical as well as for apparel textiles. Research work of the 1950s-1970s has established theoretical understanding and methods of experimental characterisation of deformation of (primarily apparel) textiles, based on descriptions on the mesoscopic structural level (unit cell of the fabric) [1]. New challenges for textile mechanics were opened when different processes of draping of composite textile performs came in the order of the day in the 1990s. Deformability of textile preforms plays a key role in the quality of a composite part formed into a 3D shape. Comparing with the earlier apparel-oriented models, textile mechanics of composite performs must include a description of their

\footnotetext{
* Corresponding author. Tel.: +32 163212 10; fax: +32 16321990 . E-mail address: Stepan.Lomov@mtm.kuleuven.be (S.V. Lomov).
}

behaviour under high loads, with deformations close to the jammed, or "locked" structures, and under combined shear - biaxial tension - compression loading conditions. Textile architectures of greater complexity need to be studied, as three-axial and three-dimensional weaves or braids, non-crimp fabrics with complex stitching patterns. Characterisation of the deformability of reinforcements via testing and/or meso-modelling of deformation provides input for macro-modelling of the drapability, used for optimisation of the preform architecture and process conditions. High cost of the materials used make adequate simulation tools essential for industry and drive the wide research efforts worldwide [2-5].

When applied to forming of composite reinforcements, experimental textile mechanics face new challenges, rising from the complexity of deformations close to the extreme states of the material and from the specific needs of the applications, which could be effectively addressed by fullfield optical measurements: 
1. Reliability of experimental devices and test protocols. We will consider picture frame and bias extension tests for shear and uniaxial and biaxial tension tests. The experimental device is supposed to apply a certain deformation to the sample; however, due to the clamping constraints the actual deformation of the sample may differ from the assumed one. Correct deformation state of the sample has to be measured with a kind of "extensometer", but measuring strain state which combines tension and shear.

2. Revealing structural meso-mechanisms of the fabric deformation and their relation with the behaviour of individual yarns. Models for prediction of resistance of a fabric to deformation and of change of the internal structure of the fabric during deformation involve certain assumptions on the yarn behaviour. For example, tension and compression of yarns are coupled during biaxial tension $[6,7]$, shear resistance of a fabric involves a combination of yarn rotation, bending, torsion and compression [8,9], etc. Reliability of the material model can be, of course, assessed by comparison of the predicted load-deformation diagram of the fabric with experimental data; however, much better confidence of a model (or more convincing critique) is created if the theoretical hypotheses could be verified by direct observation and measurement.

3. Measurement of the local deformation state of a 3Ddraped preform. Impregnation of the preform and mechanical properties of the ready 3D-shaped composite part depend on the local deformations of the preform during its draping. These deformations are predicted by drape simulation software, but all the existing drape models use simplifying assumptions for description of the behaviour of the preform (the most approximate being kinematic draping) and have to be scrupulously verified against measurement of actual local deformations of the preform.

Optical full-field stain measurements start to being used in textile deformability research quite recently, in the work of the present authors [10-19] and others [20-22]. The paper systematises these studies together with the latest results, aiming at demonstrating that state-of-the-art fullfield optical measurements are "a must" for any laboratory doing research in deformability of textile reinforcements.

\section{Full-field strain measurement: digital image correlation}

Digital image correlation (DIC) offers qualitative and quantitative information on the heterogeneous deformation of an object surface. The image correlation technique requires a sequence of digital images of a deforming object and a reference image of the object. On the object surface a random isotropic (natural or artificial) grey speckle pattern is required; for textile materials this can be natural texture of the fabric or additionally applied paint. A subset window (or correlation window) is subsequently defined in the reference image as a neighbourhood of $m \times m$ pixels that forms a unique stamp of the centre point of this neighbourhood. The speckle pattern of this neighbourhood should hold enough contrast and directional information to track the local deformation to the first order of approximation (affine transformation) by using a cross-correlation algorithm. In the correlation algorithm the centres of the neighbouring subset windows are shifted by a step size of $n$ pixels. $n$ must be smaller than the subset size to enable overlapping of the subsets (e.g. subset $15 \times 15$ pixels, and step 13 pixels). Once these settings are defined, the displacement field is calculated as an updated displacement for every subset centre. Strains are subsequently derived through differentiation of the displacement field. The differentiation algorithm uses a strain window, typically defined by the number of neighbouring $p \times p$ subset windows, thus involving a strain reference length of $m+n(p-1)$ pixels. The size of the subset window (and strain window) is a compromise of spatial resolution and noise reduction. The larger the strain field, the less noise, but also the less spatial resolution. In general one can increase both spatial resolution and reduce the noise by improving the speckle pattern or increasing the magnification factor (pixels/ length), e.g. by reducing the field of view of the camera.

Two-dimensional DIC requires one camera to be positioned perpendicular to a flat surface. The displacement field obtained is only reliable under the assumption that out-of-plane deformation can be neglected. Three-dimensional DIC requires two cameras to be installed at different angles with respect to the object. First a stereo-correlation and calibration of the camera set-up is performed from which the relative camera position and lens distortions are identified. This information is needed in the temporal matching (object tracking) and enables to estimate the DIC accuracy. From the 3D displacement fields, strains are calculated in the tangential plane of the object.

When the in-plane deformation of a textile is studied, transition from $2 \mathrm{D}$ to $3 \mathrm{D}$ measurements does not improve the quality of the measurements - on the contrary, it makes them worse. By definition, in-plane deformation of a textile is characterised by the strains of the fabric middle surface. 3D measurement gives strains in the tangential plane to a local point on the fabric surface, which is defined by micro-relief of the fabric, and which deviates largely from the middle surface - hence the strains measured by 3D DIC cannot be used to characterise in-plane deformations of the fabric. In meso-scale the 3D assessment of yarn undulations might be interesting for model verification.

\section{Materials and DIC equipment}

Table 1 lists fabrics, for which the deformability was studied with full-field strain measurements using DIC $[16,17,19,23-25]$. Four types of fabrics, representing a variety of composite reinforcements, are covered by these studies: 
Table 1

Fabrics

\begin{tabular}{|c|c|c|c|c|c|c|c|}
\hline Manufacturer's style or fabric ID & RS144/255 & R330 & R580 & RR1 & RR2 & RR3 & G1151 \\
\hline \multicolumn{8}{|l|}{ Woven fabrics } \\
\hline Weave & Twill 2/2 & Plain & Plain & Twill 2/2 & Twill 2/2 & Plain & $\begin{array}{l}\text { Interlock, } \\
\text { see Fig. } 4\end{array}$ \\
\hline Fibres & Glass & Glass & Glass & Glass/PP & Glass/PP & Glass/PP & Carbon \\
\hline Areal density, $\mathrm{g} / \mathrm{m}^{2}$ (specified) & 255 & 330 & 580 & 1816 & 1485 & 743 & 630 \\
\hline Yarns linear density, tex (specified) & 280 & 480 & 1200 & $2 \times 2400$ & $1870 / 2 \times 1870$ & 1870 & 396 \\
\hline Ends count, yarns/cm & 4.46 & 3.64 & 2.27 & 2.6 & 4.1 & 1.9 & 7.5 \\
\hline Picks count, yarns $/ \mathrm{cm}$ & 4.27 & 3.30 & 2.27 & 0.76 & 1.9 & 1.9 & 6.0 \\
\hline Warp width, mm & $1.78 \pm 0.07^{\mathrm{a}}$ & $2.67 \pm 0.11^{\mathrm{a}}$ & $3.24 \pm 0.33^{\mathrm{a}}$ & $4.58 \pm 0.52^{\mathrm{a}}$ & $3.26 \pm 0.52^{\mathrm{a}}$ & $4.35 \pm 0.59^{\mathrm{a}}$ & 1.92 \\
\hline Weft width, mm & $1.89 \pm 0.11$ & $2.56 \pm 0.10$ & $3.24 \pm 0.33^{\mathrm{a}}$ & $7.84 \pm 0.70^{\mathrm{a}}$ & $4.64 \pm 0.26^{\mathrm{a}}$ & $4.96 \pm 0.33^{\mathrm{a}}$ & 2.21 \\
\hline Crimp $^{b}, \%$ & $0.2 / 0.2$ & $0.5 / 0.5$ & $0.5 / 0.5$ & $1.9 / 0$ & $9.7 / 0.1$ & $2.0 / 2.0$ & $1.2 / 0.5$ \\
\hline Fabric ID & B1 & B2 & & & & & \\
\hline \multicolumn{8}{|l|}{ Non-crimp carbon fabrics } \\
\hline Fibre orientation & $+45 /-45$ & $0 / 90$ & & & & & \\
\hline Areal density, $\mathrm{g} / \mathrm{m}^{2}$ & 322 & 329 & & & & & \\
\hline Stitching pattern ( 7.6 tex polyester yarn) & Tricot & Tricot/chain & & & & & \\
\hline Stitching spacing, $\mathrm{mm}$ & $4.9 \times 1.7$ & $5.0 \times 2.6$ & & & & & \\
\hline
\end{tabular}

a Standard deviation.

$\mathrm{b}$ Difference between the length of the yarn in the fabric and the length of the fabric.

- glass woven fabrics, plain and twill weave, with balanced structure, areal density $250-600 \mathrm{~g} / \mathrm{m}^{2}$, made of flat rovings;

- fabrics woven from commingled glass/polypropylene thick two-strand yarns, with very unbalanced structure (zero weft crimp), areal density 700-1800 g/m²;

- non-crimp carbon biaxial fabrics, stitched (warp-knit) with thin polyester yarn;

- interlock carbon woven fabric, areal density $630 \mathrm{~g} / \mathrm{m}^{2}$.

The software for DIC and image capturing equipment:

1. The ARAMIS ${ }^{\circledR}$ software (http://www.gom.com) for DIC with $2 \mathrm{D}$ and $3 \mathrm{D}$ registration with image size $1280 \times 1024$ pixels.

2. The LIMESS software (VIC 2D) (http://www.limess. com) for DIC with $2 \mathrm{D}$ and $3 \mathrm{D}$ registration with image size $1392 \times 1040$ pixels.

3. The ICASOFT software (http://www.techlab.fr/ Strain.htm\#Icasoft) for DIC with $2 \mathrm{D}$ registration with CCD 8 bits $(1024 \times 1024$ pixels $)$ Kodak Mega + Cameras. This software has been developed at LaMCoSINSA de Lyon [26,27].

All these hard- and software are easy to use, preparation of the optical system is simple (even calibration is not needed for $2 \mathrm{D}$ measurements) and does not produce experimental "overheads". Processing of the images (calculation of the displacement/strain fields) may take few minutes; further processing of the displacement/strain fields (e.g., calculation of local shear angles, statistical parameters of the field, etc.) is done automatically (either using internal commands of the DIC software, or external processing of output ASCII files)

\section{4. "Optical extensometry" for textile deformation}

\subsection{Picture frame test}

The picture frame test [25,28-33], one of the two de facto standard tests for characterisation of the shear resistance of composite reinforcements (the second being bias extension test), measures shear behaviour of the fabric in a wide range of shear angles, up to $45-60^{\circ}$, sometimes even up to $75^{\circ}$. The scheme of the test is shown in Fig. 1. The fabric is clamped in the frame, which is mounted on a tensile machine. The load registered by the load cell of the tensile machine is recalculated into shear force (per unit fabric width) using the kinematic scheme of the frame, equivalence of the mechanical work and the shear deformation energy of the fabric (assuming homogeneous deformation state) and a normalisation method [34]. When processing the results, two assumptions concerning the deformation of the fabric sample are made:

- The shear deformation of the sample is homogeneous.

- The average shear angle of the fabric is the same as the shear angle of the frame.

DIC measurements provide data on the variations of the local shear angle of the fabric, calculated from DIC data as the angle between the diagonals of initially square facet of the image (Fig. 1b, see [16] for details of the data processing), hence estimate likely deviations from these two assumptions. Averaging the DIC-measured shear angle over the sample, one relates the measured shear force to the real fabric shear instead of to the shear of the frame; having assessed the difference between the two in relation to different test conditions, it becomes possible to validate 

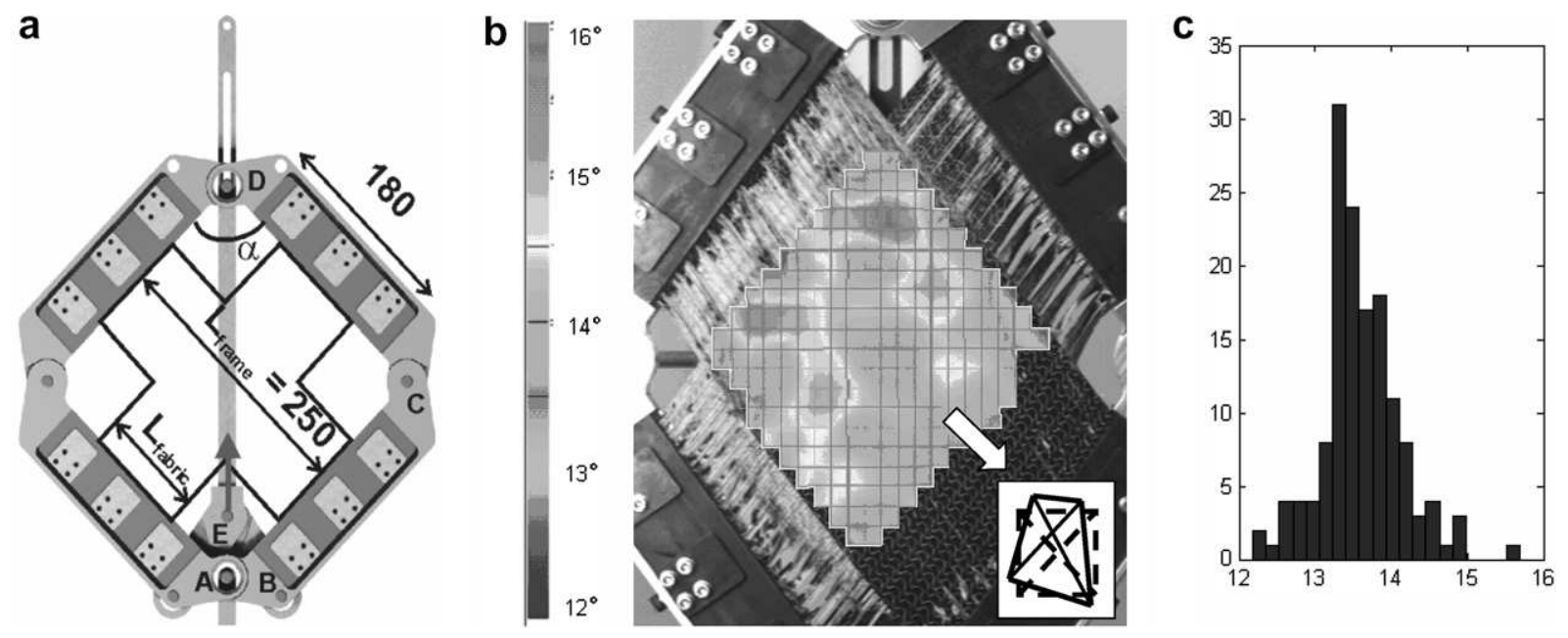

Fig. 1. Picture frame: (a) the device; (b) typical shear angle field for fabric B2, frame shear angle $14^{\circ}$; inset: scheme for calculation of the local shear angle (c) histogram of the distribution of the shear angle (frame shear angle $14^{\circ}$ ).

(or disqualify) results obtained without full-field strain measurement.

Looking on the example of the registered field (Fig. 1b and c) one notices that the shear angle field is indeed reasonably homogeneous (average $13.5^{\circ}$, standard deviation $\left.0.5^{\circ}\right)$. The extreme values of the local shear $\left(12^{\circ}\right.$ and $\left.16^{\circ}\right)$ are very localised or happen at the edge of the image, where the precision of the DIC algorithms is low. Table 2 gives an overview of the parameters of the shear angle scatter in a sample for all the studied fabrics (measurements with ARAMIS system). A frame shear angle of $30^{\circ}$ is chosen as a representative reference. For all the fabrics, not withstanding the difference in tightness, balance, thickness of the yarns or even architecture (woven-NCF), the standard deviation of the shear angle scatter lies between $0.5^{\circ}$ and $2.2^{\circ}$, or $1.5-7.3 \%$. The highest value of $2.2^{\circ}(7.3 \%)$ is reached for the highly unbalanced and thick fabric RR2.

It is recommended to use DIC measurements routinely to validate this homogeneity (hence the correctness of the sample mounting) in a particular study.

Two mechanisms leading to the difference between the shear angle of the frame and average shear angle of the fabric can be identified, depending on the size of the sample in relation to the size of the frame (Fig. 2).

When the sample size is close to the size of the frame (Fig. 2a, "large sample configuration") and especially when the "arms" of the sample (connecting the central part with

Table 2

Difference between the local shear angle and average shear angle of the fabric at the frame shear angle of $30^{\circ}$, average values in five tests

\begin{tabular}{llllllllll}
\hline & $\begin{array}{l}\text { RS144/ } \\
255\end{array}$ & R330 & R580 & RR1 & RR2 & RR3 & B1 & B2 \\
\hline $\begin{array}{l}\text { Maximum positive } \\
\text { difference }\end{array}$ & 3.1 & 3.0 & 1.5 & 4.8 & 6.0 & 4.8 & 1.8 & 1.6 \\
$\begin{array}{c}\text { Maximum negative } \\
\text { difference }\end{array}$ & 3.7 & 2.6 & 0.8 & 4.0 & 5.8 & 4.9 & 2.1 & 2.0 \\
$\begin{array}{c}\text { Standard deviation of } \\
\text { the difference }\end{array}$ & 1.3 & 1.2 & 0.5 & 0.8 & 2.2 & 0.7 & 0.65 & 0.74 \\
\hline
\end{tabular}

the frame clamps) are kept intact, the bending of the yarns near the frame clamps affects the fabric shear. The dotted line in Fig. 2a shows the yarn path, which is close to the normal to the frame side near the gripping (line 1). Line 3 , connecting the points of gripping of the yarn, is parallel to the frame side. Hence, shear angle of the yarn, defined by its direction (line 2), tends to be larger then the angle of the frame.

When the bending stiffness of the arm parts is low (Fig. 2b, "small sample configuration"), a different mechanism works. The shear deformation of the frame cannot be any more transferred to the sample through shear/bending deformation of the arms. This has to be done purely by tension of the arms as shown in Fig. 2c. The corresponding deviation of the yarns in the arms from the non-tensed ideal paths (shown as dashed lines) makes the fabric shear to retard behind the frame deformation, and the fabric shear angle is less then the frame shear.

The two mechanisms work together when the yarns are not taken out of the "arms" of the sample, leading to the combined effect of positive (the first mechanism) and negative (the second) difference between the fabric and the frame angle.

Fig. 3 show the results of DIC measurements for all the fabrics ([16,23], measurements with ARAMIS system). The graphs of Fig. 3 slightly differ from the previously published in $[16,23]$ due to the corrected processing of the frame kinematics; the changes do not affect the conclusions of $[16,23]$. Fig. 3 shows the data for both large and small sample configuration for RR2 sample only; other graphs give data for large sample configurations.

There are two different patterns of the difference between the fabric and frame shear angle for the "large centre" configuration:

- Not-too tight, not-too-heavy (areal density well below $1000 \mathrm{~g} / \mathrm{m} 2$ ) woven fabrics RE144, R330, R580, RR3 and NCF B1 and B2. The difference is mainly negative, 

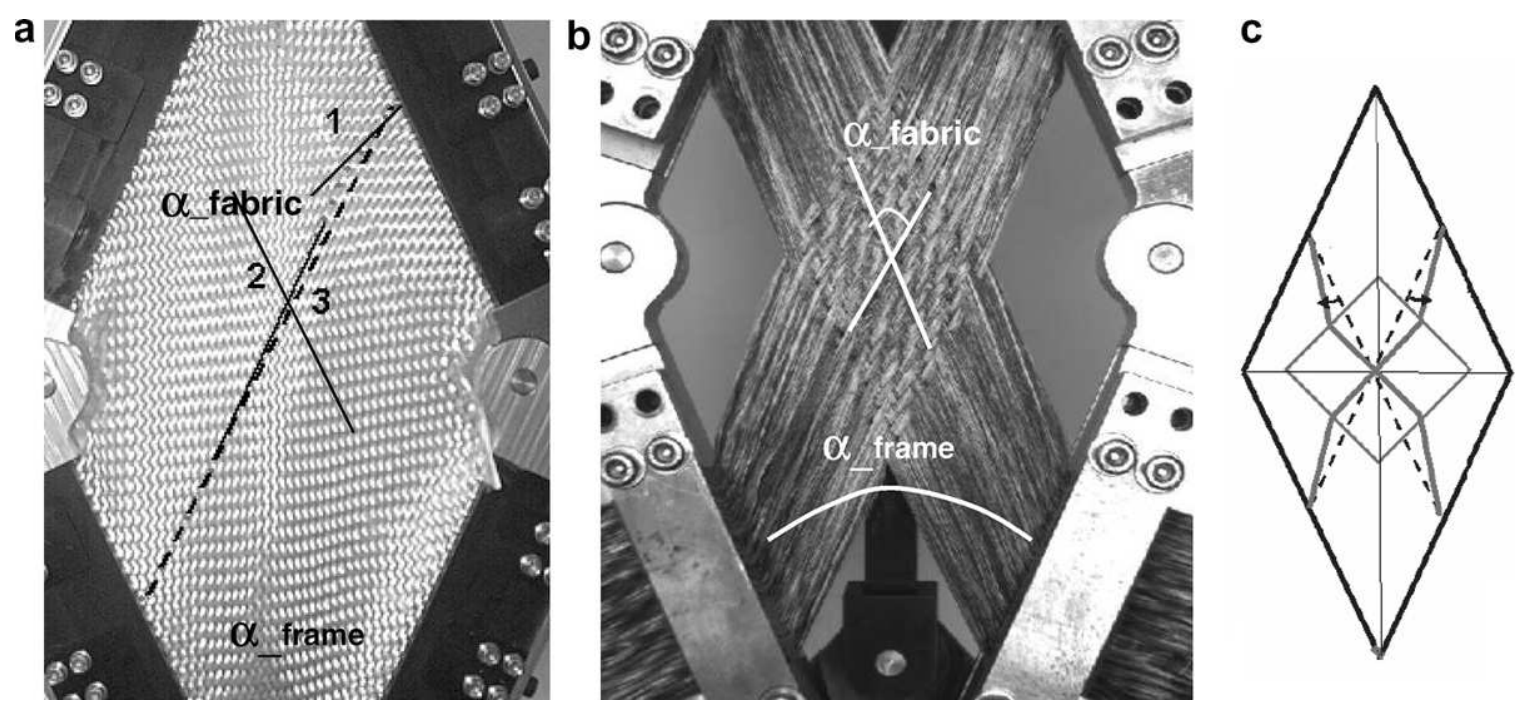

Fig. 2. Two types of samples on picture frame: (a) large sample, fabric shear is higher then the frame shear; (b) small sample, yarns in the "arms" are drawn out, fabric shear is less then the frame shear; (c) scheme of the positions of the yarns in the case (b).
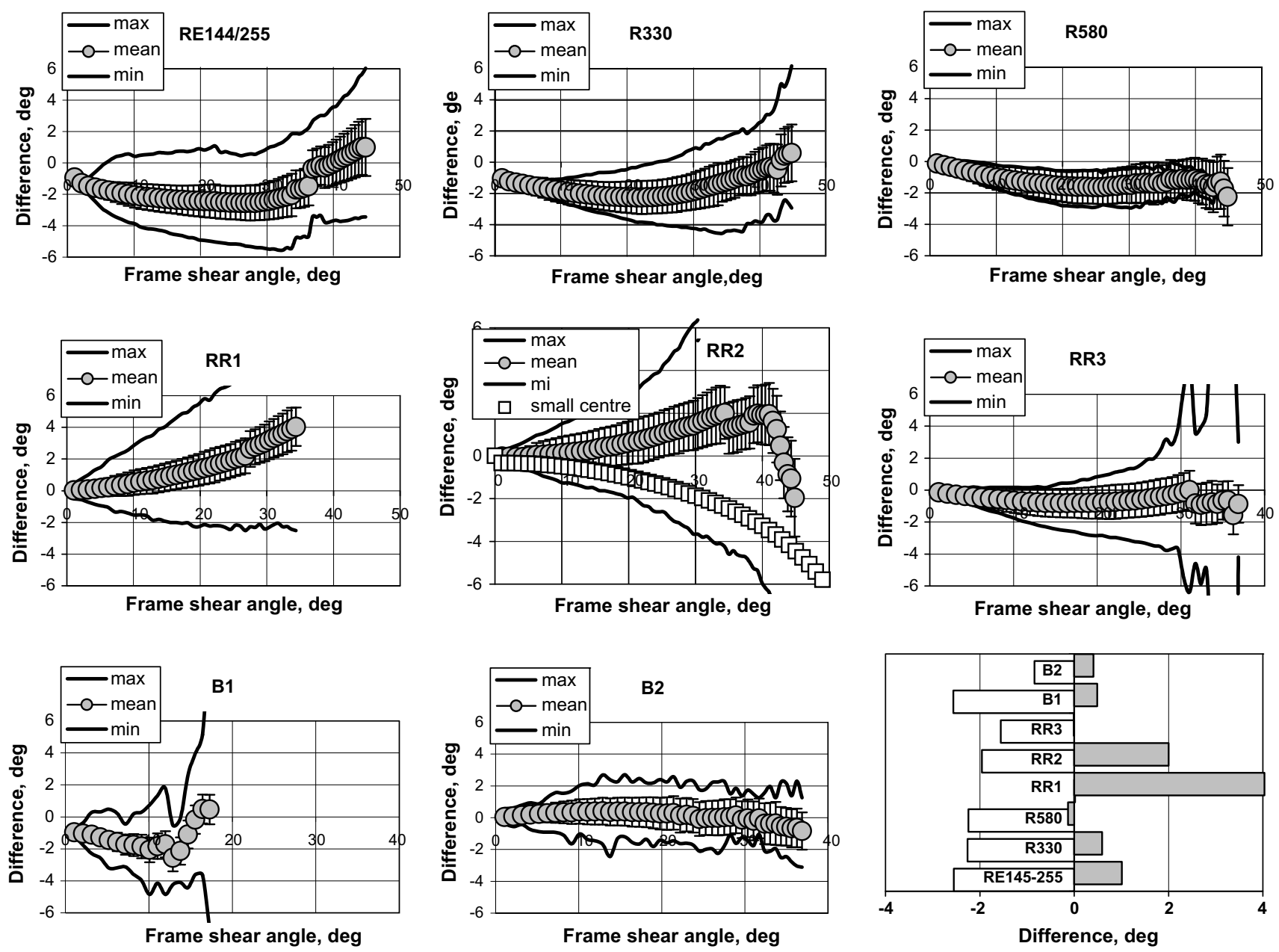

Fig. 3. Difference of the average shear angle of the fabric, measured using DIC, and shear angle of the frame. Graph for RR2: large and small sample configuration; other graphs: large sample configuration. Error bars indicate standard deviation in five tests. The last diagram: minimum and maximum differences for all the tested fabrics, large sample configuration. 
with the positive values at the end of the graph. The difference is not greater than $2^{\circ}$.

- Tight heavy woven fabrics RR1 and RR2. The difference is positive, and reaches value of $4^{\circ}$, which by no means is negligible value in composite forming.

These differences between shear obtained by optical measures and the shear of the picture frame are in good agreement with those presented in [25].

DIC measurements (LIMESS system) for the "small centre" configuration of fabric RR2 confirm the mechanism explained above for this type of samples (Fig. 3, RR2). The difference between the average fabric shear angle and shear angle of the frame is negative. It is of the same order of magnitude as positive value for large sample configuration. It may be interesting to optimise the sample configuration minimising this difference.

We can conclude that DIC measurements reveal differences between the actual strain state of the sample and the strain imposed by the picture frame. The differences can be significant and "optical extensometry" should be routinely used in picture frame tests to ensure adequate results. The data presented in Fig. 3 can be used for estimation of errors in measurements done without full-field strain registration.

\subsection{Bias extension test}

For in-plane shear behaviour measurement, the "bias test", i.e. a tensile test at $45^{\circ}$ is an alternative to the picture frame analysed above. In this experiment, a tensile test is performed on a rectangular specimen in which the warp and weft directions of the tows are orientated initially at $\pm 45^{\circ}$ to the direction of the applied tensile load (Fig. 4) [21,35-39]. When the specimen is stretched from $L$ to $L+d$ (see Fig. 4 for notations), the possible motion between the yarns and their large tensile stiffness lead to the deformed shape shown Fig. 4c. In zone A the warp and weft yarns have both a clamped end and there is no deformation in this zone. The zone $\mathrm{C}$ is the active zone of the test. The warp and weft yarns have free ends. The non-sliding at crossovers and the global stretching of the specimen leads to a pure shear deformation related to $d$, the displacement of the mobile grip. In zone $\mathrm{B}$, one yarn direction is clamped at one end, the other direction is free at both ends. The global stretching of the specimen leads to a shear strain of a value half of that of the zone C.

In this test the zone $\mathrm{C}$ is in pure shear. The first advantage of this test with respect to the picture frame lies in its simplicity of implementation. In addition the yarns of the central zone in pure shear are free at their ends. Consequently they are not subjected to tension (or to very weak one). The nature of the test thus leads more naturally to a shear state without tension than the picture frame test. Conversely the intermediate zones B make the test analysis more delicate because the force measurement on the machine is global and concerns the deformation of all zones at the same time.

The measure of the load on the tensile machine and the measure of the shear angle $\gamma$ give the shear load per unit fabric width.

DIC measurements are made to determine the shear angle during the bias extension test. Fig. 5 show results of the optical measurements for $30 \mathrm{~mm}$ and $70 \mathrm{~mm}$ grid displacements ( $5 \mathrm{~mm}$ displacement increments) that correspond to theoretical shear angles in central zone $\mathrm{C}$ equal to $18.8^{\circ}$ and $55.3^{\circ}$, respectively. The textile reinforcement is a $\mathrm{G} 1151^{\circledR}$ interlock fabric. From the DIC data, the software ICASOFT $[26,27]$ calculates the rotation $R$ of the polar decomposition $F=R U$. From these polar rotations on two warp and weft yarns, the angle variation $\gamma$ is calculated.

Table 3 shows, for the different grip displacements, the value of the shear angle $\gamma$ obtained by the optical measurements and the theoretical values deduced from the geometry (shown in Fig. 4c). In the first part of the loading, i.e. for shear angle smaller than $40^{\circ}$, there is only a small difference between theoretical and measured angle. For displacements corresponding to shear angle larger than $45^{\circ}$, the difference between measured and theoretical shear angles become important in the central part of the specimen (zone C). For these angles the kinematics of the bias test is no more the theoretical one. This is probably due to sliding between the warp and weft yarns (see [22]).

The load versus shear angle diagrams obtained from this bias test are discussed in Section 5 together with the analysis of mesoscopic deformations.

\subsection{Biaxial tension}

Biaxial tension tests with full-field strain registration were performed with samples of fabric RR2. The biaxial tensile machine (Fig. 6a) is made up of four rigid U-shaped grip bodies, each mounted on a ball-screw spindle and actuated by a DC motor. The velocity can be controlled independently in both tensile directions. Grip displacement was measured with laser sensors over the grips, to avoid any influence of machine compliance. Tests were performed with warp/weft velocity ratio $1 / 1$ (equal velocities) and $1 /$ free (uniaxial warp test), at velocity $0.1 \mathrm{~mm} / \mathrm{s}$ and $1 \mathrm{~mm} / \mathrm{s}$ at room temperature. For every test condition, three repeats have been undertaken. Optical measurements were performed using the ARAMIS system. All crossshaped square specimens contain 28 warp and 14 weft yarns (Fig. 6b). As a standard the unloaded yarns in the arm parts are removed (left-hand side of Fig. 6b). Three samples were tested without yarn removal (right-hand side of Fig. 6b) in order to compare the influence of sample preparation on field homogeneity. The side of the woven central part is about $70 \mathrm{~mm}$.

The same questions as for the picture frame tests can be presented: is deformation of the sample homogeneous? 
a

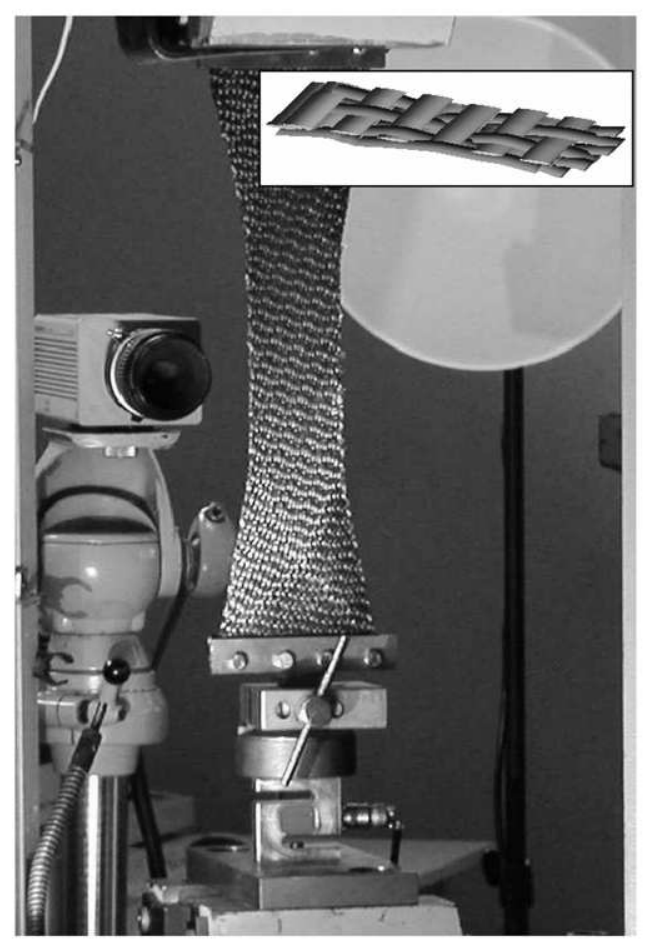

b

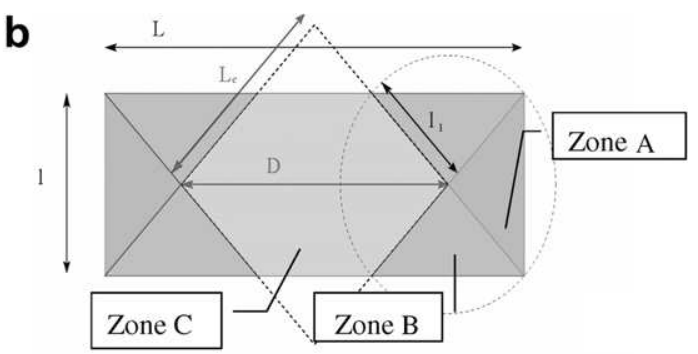

C
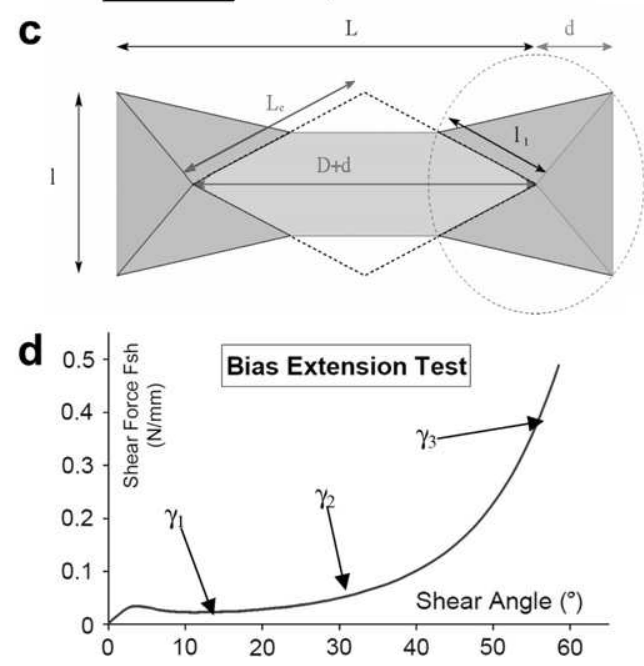

Fig. 4. Bias extension test: (a) the device (inset: weave structure of the fabric G1151); (b) initial rectangular specimen with yarns oriented at $\pm 45^{\circ}$; (c) deformed specimen; (d) shear load curve for G1151 interlock fabric. Angles calculated from the mesoscopic analysis.

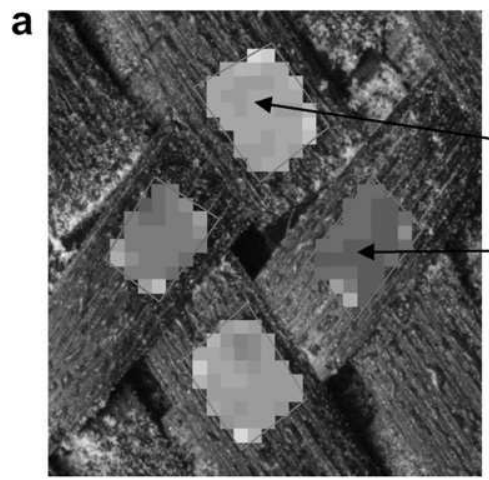

C

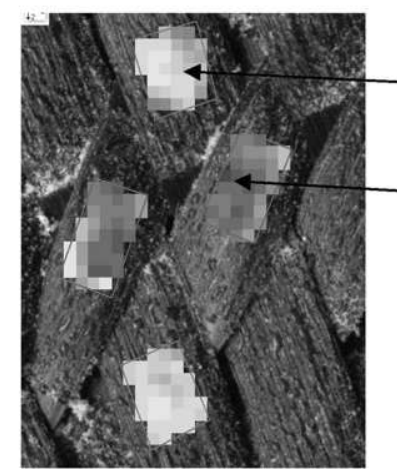

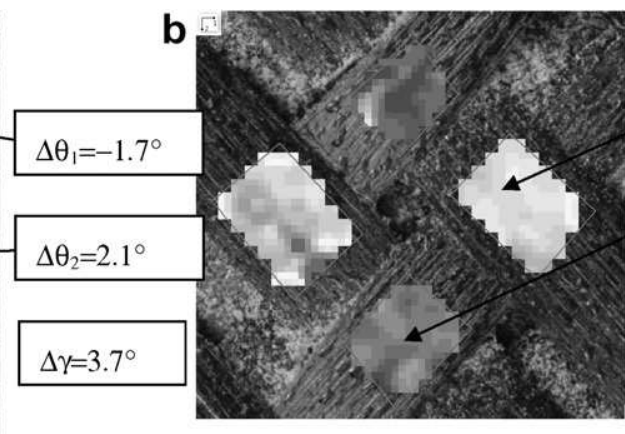

$\Delta \theta_{1}=-0.1^{\circ}$

$\Delta \theta_{2}=1.7^{\circ}$

$\Delta \gamma=1.8^{\circ}$

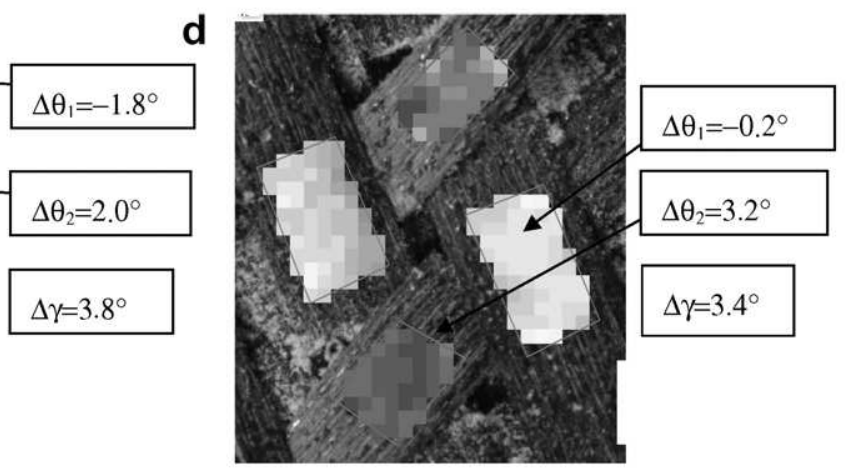

Fig. 5. Optical measurements of the polar rotation $\Delta \theta$ and the shear angle $\Delta \gamma$ on warp and weft yarns during a bias extension test for displacement of the grip from $25 \mathrm{~mm}$ to $30 \mathrm{~mm}$, in zone C (a) and B (b) and for displacement of the grip from $65 \mathrm{~mm}$ to $70 \mathrm{~mm}$, in zone C (c) and B (d).

Does it correspond to the deformation applied by the instrument?
The tests at velocity ratio $1 / 1$ with and without removal of the yarns in the arm part show only significant differ- 
Table 3

Comparison of measured (DIC) and theoretical shear angles in zones $\mathrm{C}$ and $\mathrm{B}$

\begin{tabular}{lccclc}
\hline $\begin{array}{l}\text { Grip displacement } \\
(\mathrm{mm})\end{array}$ & \multicolumn{2}{l}{ Shear angle $\gamma\left({ }^{\circ}\right)(\mathrm{DIC})$} & \multicolumn{2}{l}{$\begin{array}{l}\text { Theoretical shear angle } \\
\gamma\left({ }^{\circ}\right)\end{array}$} \\
\cline { 2 - 3 } & Central zone & Zone & & Central zone & Zone \\
& $\mathrm{C}$ & $\mathrm{B}$ & $\mathrm{C}$ & $\mathrm{B}$ \\
\hline 5 & 1.82 & 1.44 & 2.90 & 1.45 \\
30 & 22.09 & 7.41 & 18.81 & 9.40 \\
50 & 34.79 & 16.48 & 34.22 & 17.11 \\
70 & 47.34 & 28.80 & 55.33 & 27.67 \\
80 & 55.59 & 39.22 & 73.73 & 36.87 \\
\hline
\end{tabular}

ences in field uniformity for the very exterior yarns of the rectangular centre (Fig. 6c). The local variability of the field represents the woven structure of the fabric: each hill/valley corresponds to an element of the woven structure of the fabric. The shear field (Fig. 6d) gives another assessment of quality of the biaxial tension strain state of the sample: the shear (which ideally should be zero for the biaxial tension test) is limited to maximum values of $1.5^{\circ}$.

Fig. 7 shows the tensile diagrams in warp and weft direction, using both local strain from full-field strain measure- ments and enforced strain from displacement of the clamps. In weft direction the deviation between the curves measured at the clamps and those using DIC remain within the accuracy of the measurement. In warp direction, however, the deviations become quite significant. For the test with ratio $1 /$ free (uniaxial) the offset reaches $3 \%$ strain, which is comparable to the whole non-linear region of the diagram. The use of the clamp displacement data would introduce then a gross error of the estimation of the initial "slackness" of the fabric, which affects significantly its behaviour in forming.

An explanation of the difference in behaviour in the warp and weft direction lies in the unbalanced nature of the fabric. The weft yarns are not crimped (see Table 1); hence the clamp movement in the weft direction is directly transferred to the sample. The warp, contrary, is heavily crimped (crimp is 9.7\%). Consider the samples with removed yarns in the arms. The tension of the straight yarns in the arms is transferred to the central sample via complex interaction of the yarns, causing their decrimping, which delays the deformation of the central part and increases the non-linear part of the diagram. The effect is most pronounced for uniaxial tension; for biaxial 1/1 load- a

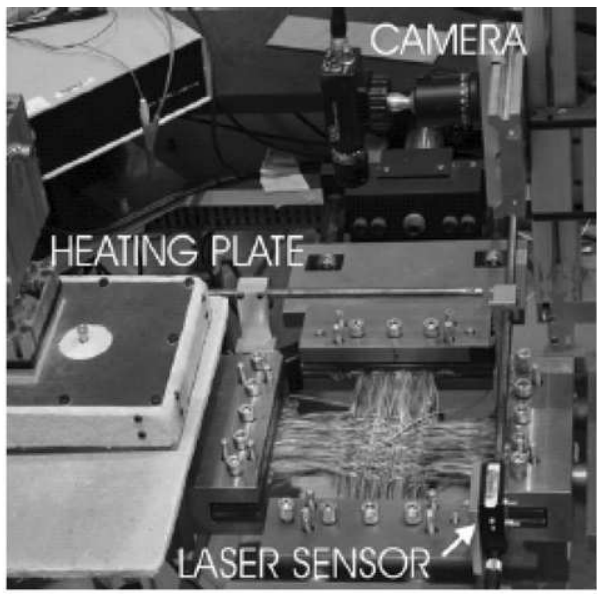

C

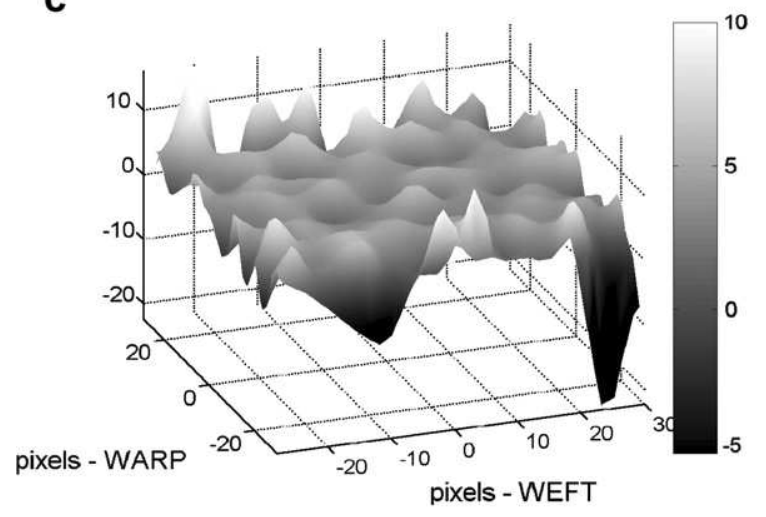

b
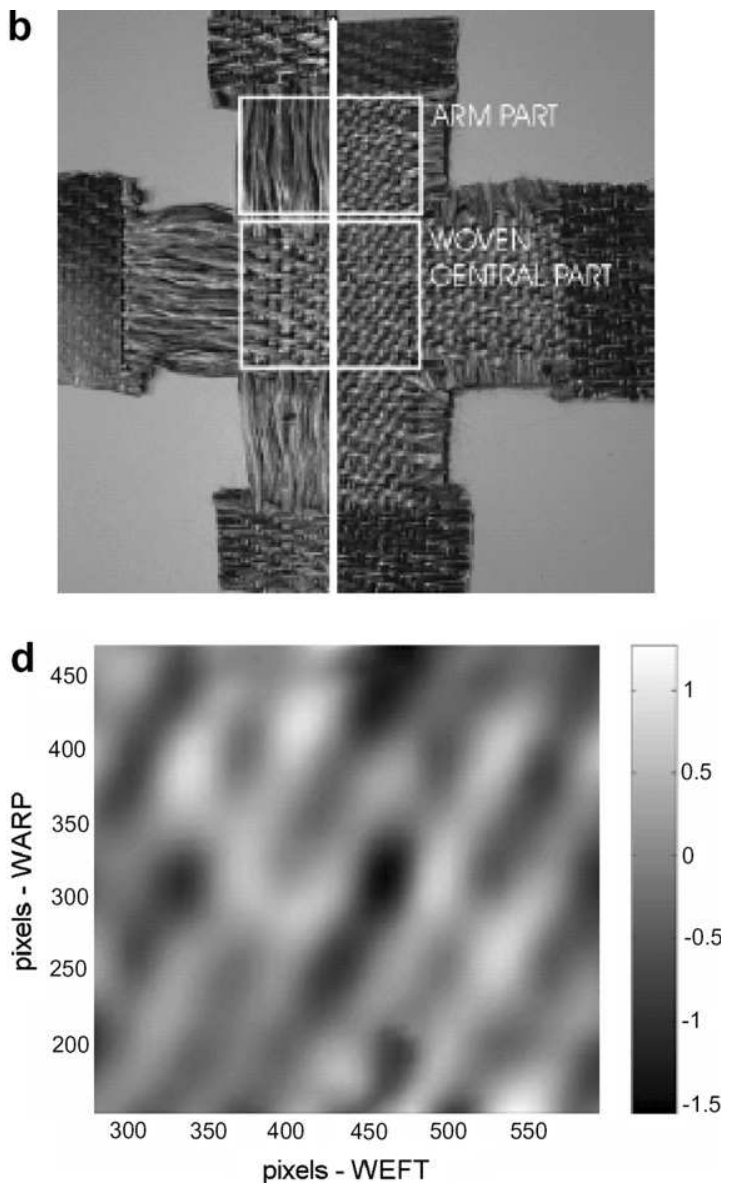

Fig. 6. Biaxial tensile machine: (a) general view; (b) samples, left: side yarns removed; right: no side yarns removed; (c) homogeneity of the tensile strains: first invariant field for test 1/1 with yarns removed; depicted is whole central area minus one yarn on the circumference; applied strain: $1.17 \%$ in weft, $2.23 \%$ in warp; (d ) Shear angle field (degrees) for test $1 / 1$ with yarns removed; depicted is the whole central area minus three weft yarn and five warp yarns on the circumference. 

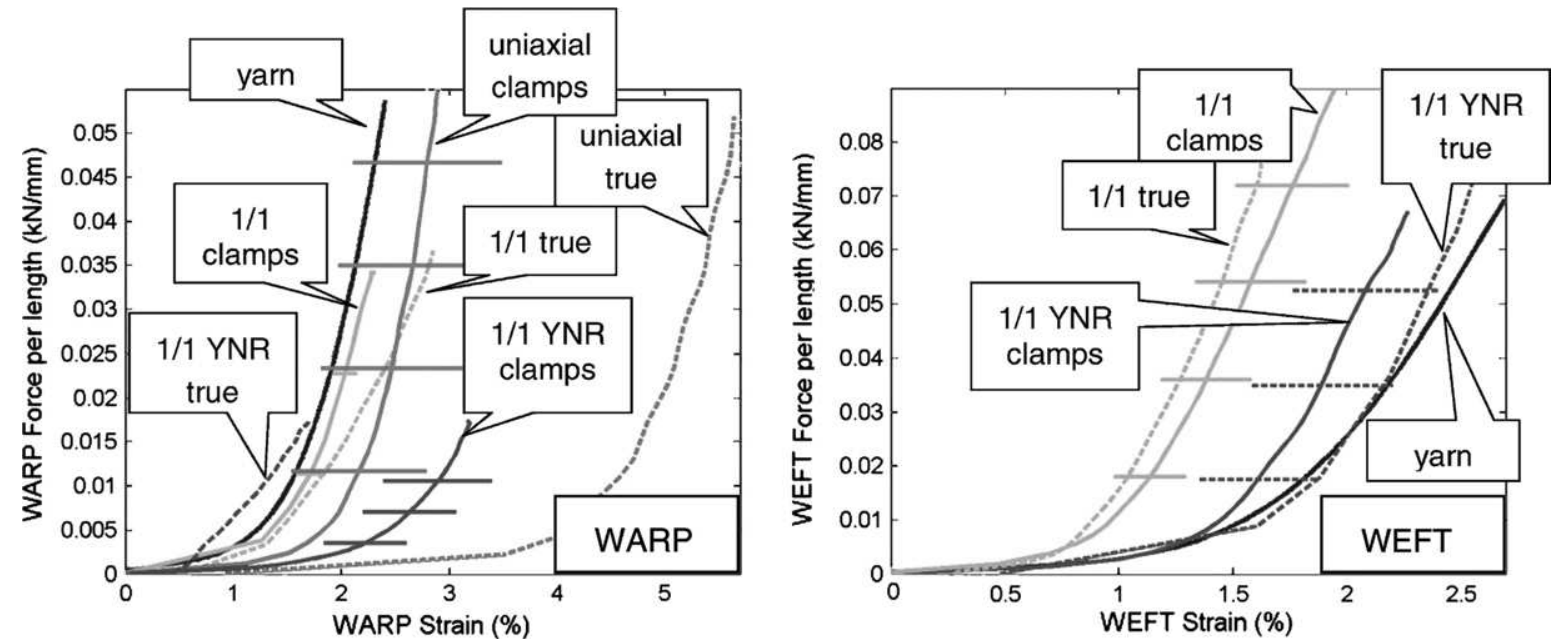

Fig. 7. Tensile diagrams in warp and weft direction, based on DIC-measured average sample strain ("true") and enforced strain ("clamps"), for samples with yarns removed (-) and not removed (YNR), together with tensile diagrams of the yarns.

ing the tension in the weft yarns prevents intensive decrimping of the warp, and the difference of the sample deformation and clamps movement is reduced. For the samples with non-removed yarns in the arms the effect is reversed: movement of the clamps is transformed into much lesser strain in the central part (1/1, warp direction). This is due to the free (unclamped) weft in the arms. Because of this, the central part (where weft is clamped and moreover, tensed) is much stiffer then the arms, which explains the difference in the warp strain.

The difference of the sample strain and the imposed strain leads to an important difference of the actual ratio of strain in warp and weft directions from the ration of $1 / 1$ imposed by the speed of the machine. In the $1 / 1$ test, for instance, the actual velocity rate measured by the laser sensors is about 1.2, whereas the velocity ratio in the fabric is 2 for the test with loose yarns removed, and variable between 0.27 and 2 in the test without loose yarns removed. This difference in biaxial loading is very large and can lead to inadequate conclusions when the experiment is used as benchmarking for a fabric deformation model or can lead to errors in forming simulation when a biaxial test is used to provide input data for them.

We can conclude (also taking into account the results of [24]) that whilst the strain homogeneity in biaxial test has proven to be acceptable, the reliable assessment of the actual strain of the sample is possible only using direct measurement of the strain of the sample using an optical strain gauge.

\section{Meso-scale strain fields: revealing mechanisms of fabric deformation}

As it has been seen in the previous sections, optical fullfield measurements performed on the specimen permit to measure the actual kinematic quantities - strain state of the sample - and to verify the homogeneity of the strain fields. These measures can be qualified as macroscopic because they consider the fabric as a continuous material, the mechanical behaviour of which is analysed in shear, tension, etc. A second important possibility offered by optical field measurements is the analysis of the fabric deformation at lower scale. A textile is a hierarchically organised multiscale material. If the scale of the textile or of the specimen is called macroscopic (and measured in centimetres or decimetres), the scale of the yarn or of the textile unit cell is the mesoscopic scale (measured in millimetres). The yarn is made of hundreds or thousands fibres and the scale of the fibre is called microscopic (some micrometres).

The DIC optical measurement can be performed on a smaller domain and especially on a woven yarn. The main interest of such analysis is to address internal deformation mechanisms of fabrics. It permits to show that the strain in the yarn may be different from the global macroscopic strain in the fabric. The case of an in-plane shear "bias test" will be considered here; mesoscopic deformation of yarns in shear test are analysed using DIC in $[14,16,25]$. Such analysis can also be done for other elementary tests such as tensile or bending tests.

The DIC analysis is performed at the mesoscopic level, i.e. on a zone small enough to be within a single yarn. Fig. 8 shows the incremental displacements fields at different stage of the shear load curve shown in Fig. 4d. The textile reinforcement is a G1151 interlock fabric (Table 1). The drawn vectors show the displacement relatively to the centre of the analysed zone. The angles $\gamma$ and $\gamma^{*}$ refers to the shear angles in the zones $\mathrm{C}$ and $\mathrm{B}$ (Fig. $4 \mathrm{~b}$ and c).

For a moderate shear (grip displacement $d=30 \mathrm{~mm}$, shear angle $\gamma=22^{\circ}$ in the zone C) it appears (Fig. 8a) that these displacement vectors are perpendicular to the radius vector "the centre of the analysed zone - the point under consideration" and have a norm proportional to the distance to the centre - rotation field. Hence the yarn is subjected to a rigid body motion (rotation + translation of the centre). The macroscopic shear strain of the specimen is created by the relative displacement of the different yarns. 

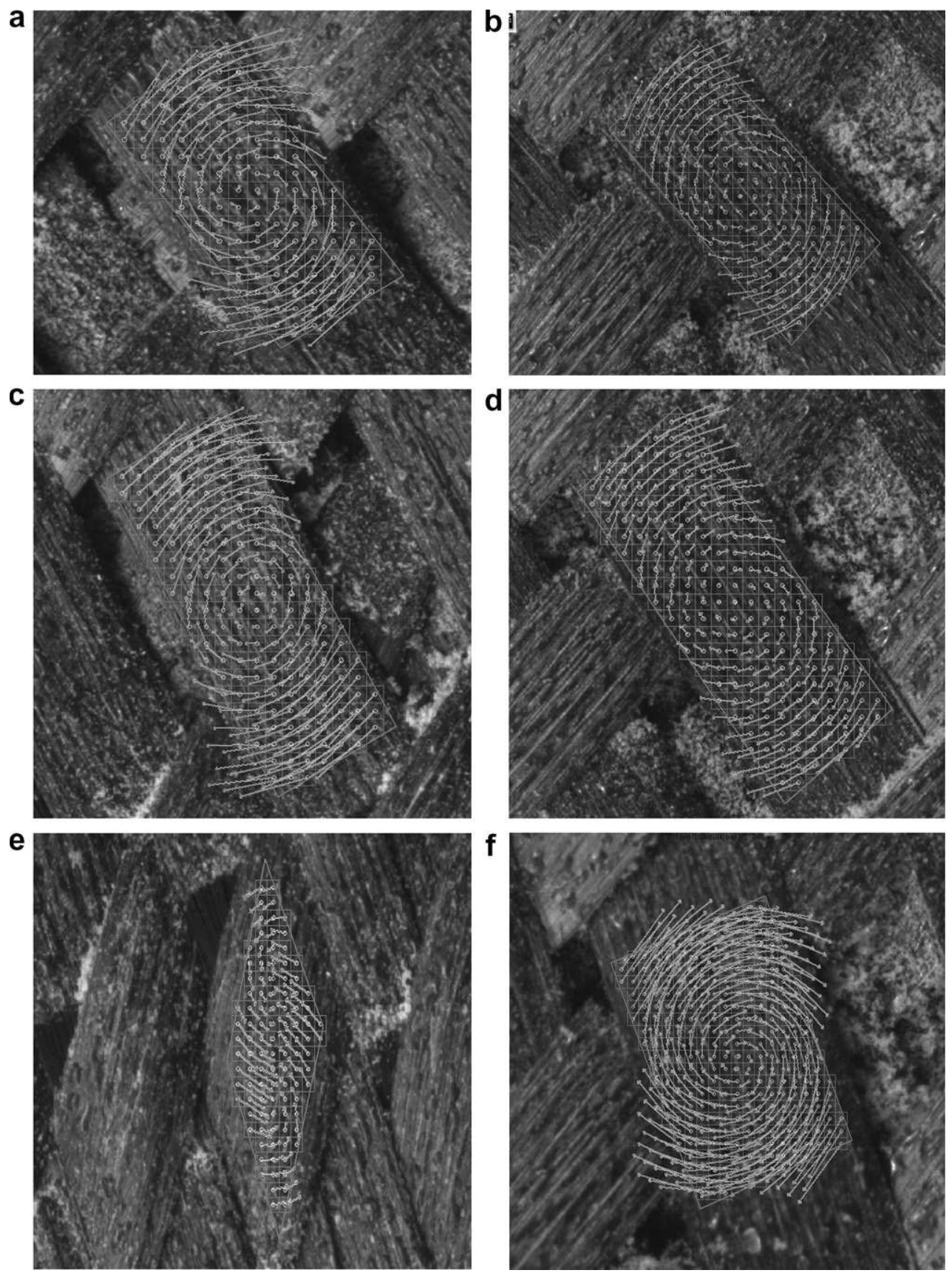

Fig. 8. Meso-scale analysis: displacement fields within a yarn. (a) Central zone $\mathrm{C}$ for $d=30 \mathrm{~mm}, \gamma=22^{\circ}$; (b) zone B, $d=30 \mathrm{~mm}, \gamma^{*}=8^{\circ}$; (c) central zone $\mathrm{C}$ for $d=50 \mathrm{~mm}, \gamma=35^{\circ}$; (d) zone B, $d=50 \mathrm{~mm}, \gamma^{*}=16^{\circ}$; (e) central zone C, $d=80 \mathrm{~mm}, \mathrm{C}, \gamma=56^{\circ}$; (f) zone B, $d=80 \mathrm{~mm}, \gamma^{*}=39^{\circ}$.

The strain field within the yarn is null or very weak. In the intermediate zone $\mathrm{B}$, the displacement field is also a rotation field but with displacements twice smaller (Fig. 8b).

For a grid displacement $d=50 \mathrm{~mm}$, the incremental displacement fields are, as well, close of rotation fields in both zone $\mathrm{C}$ and $\mathrm{B}$ (Fig. $8 \mathrm{c}$ and d). Nevertheless this begins to be less true in the central zone $\mathrm{C}$ (Fig. 8c) where the displacements with a given norm start to be on an ellipse.

When the shear angle becomes large $(d=80 \mathrm{~mm}$, $\gamma=55^{\circ}$ ), the relative displacement is no more a rotation field (Fig. 8e). The shear angle and the geometry of the woven fabric lead to a transverse compression field. This compression field is added to the rotation field. The yarn is no more in a rigid body motion, it is strained but its strain field is not a shear strain but a transverse compression field. The similar compression was noted for the picture frame test in $[14,16,25]$.

For the same grip displacement $\left(d=80 \mathrm{~mm}, \gamma=55^{\circ}\right)$, it can be seen (Fig. 8f) that the intermediate zone B is still subjected to a rotation motion. Because the shear angle is twice smaller in this zone, there is not yet yarn compression. 
This meso-scale analysis shows that the deformation within a yarn can be very different of the global macroscopic deformation. This macro-deformation is mainly due to the relative displacements between yarns.

This analysis has been made in the case of the bias test but it could be interesting to perform such meso-scale measurements for other elementary loadings such as biaxial tensions or bending. For instance it has been shown by computations at meso-scale level (i.e. 3D finite element analyses of the unit woven cell) that the transverse compression of the yarn is very important and is a main aspect of biaxial tests [40]. Optical measures of this compression would be interesting. Meso-scale analysis have been performed in the case of the picture frame tests and the conclusions are in agreement with those obtained above for the bias test $[14,16,25]$.

The analyses are performed in this paper on "dry" textile reinforcements, i.e. without any resin. The conclusions can be different in case of preimpregnated textile reinforcements because the resin is a brake to relative displacement of the yarns [41].

\section{Local deformations of a 3D-shaped preform}

The grid strain analysis (GSA), also called "grid method", is used to study sheet forming of metals [42] and composites $[43,44]$. This technique requires a grid pattern, attached to the material, in order to track the displacements of the crossings. The DIC is used to measure these displacements. The grid method is very convenient for cases where large local deformations (and phase changes, like polymer melting) occur, since in these cases a random speckle pattern would often be destroyed and become useless.

In this study the local deformations are measured on a thermoformed cylindrical-shaped part (Fig. 9a) of a glass/PP preform (fabric RR2, Table 1), as reported in [45]. In order to track the fibre orientations during forming, a reference pattern is sprayed with white paint onto the black pre-consolidated sheets with the help of a stencil that has parallel grooves. The pattern consists of a grid, with a grid size of $5 \times 5 \mathrm{~mm}$ and a line thickness of about $1 \mathrm{~mm}$. After forming, the composite part is measured with the LIMESS system using the DIC technique. By interactively extracting the coordinates of the grid intersection points, the angles between the grid lines are calculated using the planimetric law of cosines: $\alpha=\Varangle(\mathrm{AB}, \mathrm{AC})$. A shear angle at the point $\mathrm{A}$ is then calculated as average of four angles $\gamma$, complimentary to the four angles $\alpha$ for the grid lines joining at $\mathrm{A}$ (Fig. 9c).

Fig. 9b shows the set-up of the LIMESS system to obtain the surface information. The result is indicated in Fig. 9c, namely a correlated surface overlaid on a picture of a deformed sheet. In Fig. 9d the shear angle distribution obtained from this surface is depicted. Note that the light reflections can corrupt the DIC measurements at certain places ("empty" square in Fig. 9d).

The main benefit of this technique lies in the fact that the surface is measured via a contactless method. Drawbacks lie in difficulties of tracking the fibre directions. When applying the reference pattern on the pre-consolidated sheets, it is assumed that the gridlines are parallel with

a
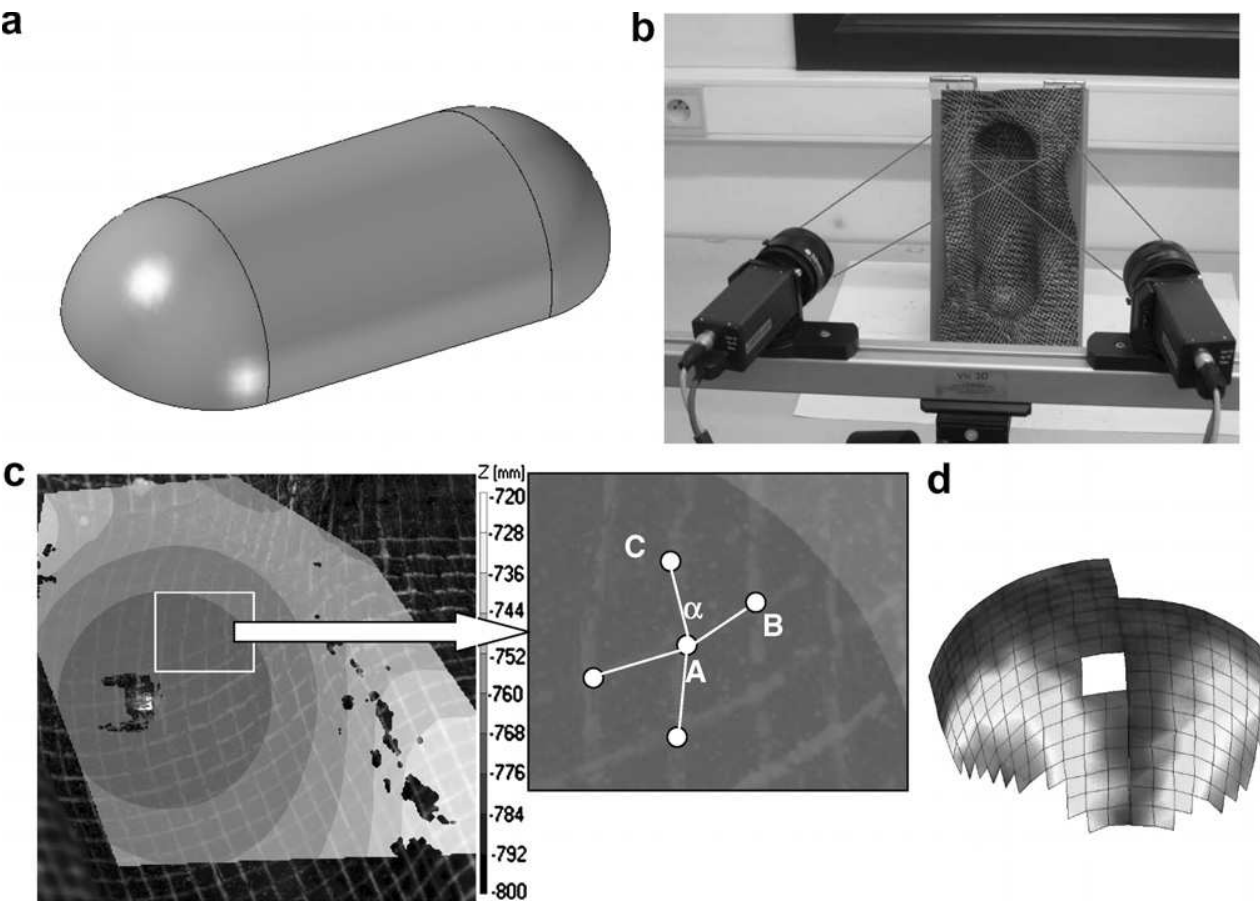

d

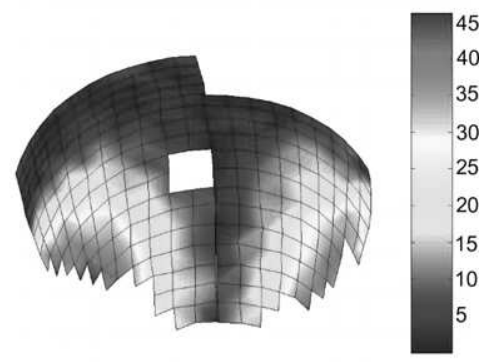

Fig. 9. Measurements of the local deformations of the shaped preform: (a) the mould; (b) set-up of LIMESS measuring system; (c) a correlated surface that depicts the $z$-coordinate of the surface in grey-scale overlaid on a picture of a deformed sheet; (d) calculated shear angle distribution. 
the fibre directions. In practice fibres inside the sheet are not perfectly straight, which makes it impossible to track them flawless. Another reoccurring phenomenon is the destruction of the reference pattern due to friction between the mould and the deformed fabric, especially pronounced in high shear zones.

The experimental local deformations are subsequently compared with the predictions of a kinematic drape model (QuikForm). Different blank-orientations, specified as the angle between warp yarns and the long symmetry axis of the mould are also taken into consideration and the results are plotted in Fig. 10. The kinematic draping model adequately predicts the fibre orientations for the 0 and $90^{\circ}$-orientation of the blank. It is believed that the discrepancy between the model and the measured values at higher shear angles is due to the fact that the shear resistance increases rapidly when the locking angle $\left(40^{\circ}\right.$ for the studied fabric [46]) is reached, and the assumption of the negligible shear resistance is no more valid. For other orientations the kinematical model gives faulty predictions of the fibre orientations after draping as illustrated in Fig. 10b. This erroneous result is due to the draping approach of the model, as it starts to drape the mould from a single point, while in reality the draping starts from a line of first contact. Kinematic approach of modelling is too elementary to predict the correct fibre
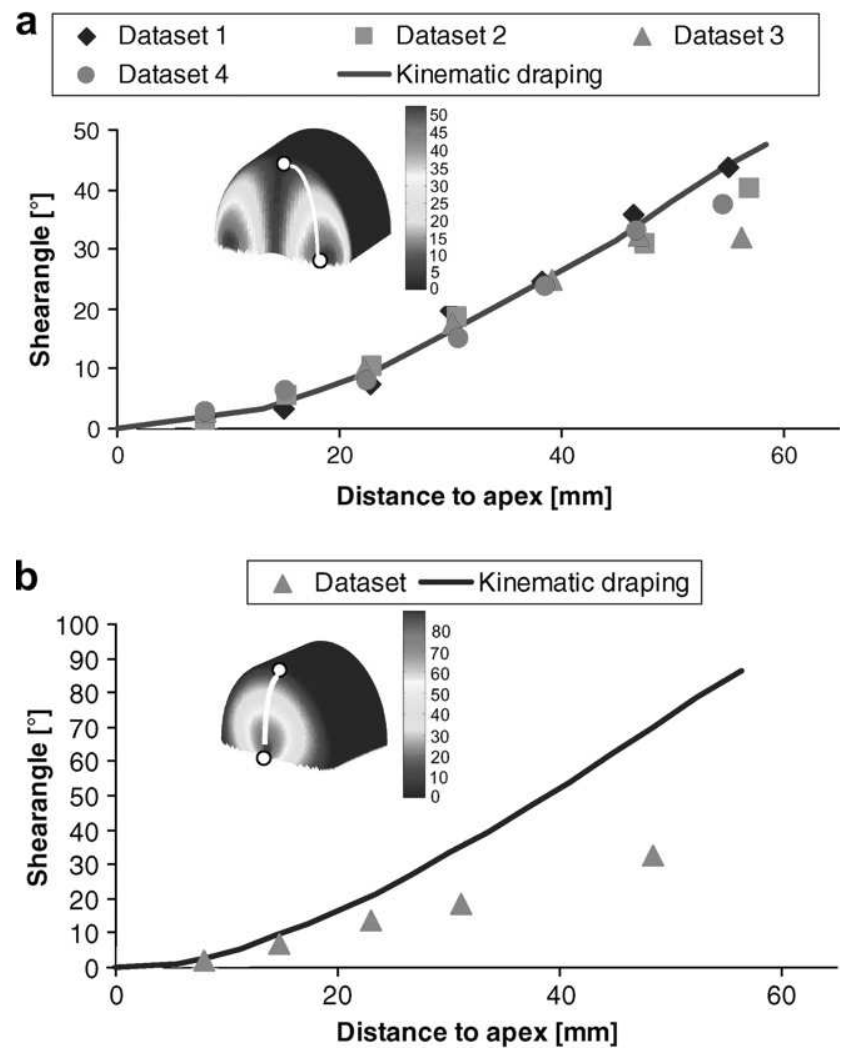

Fig. 10. Comparison of the measured shear angles and those obtained via a kinematical modelling approach for two blank-orientations: (a) $0^{\circ}$; (b) $45^{\circ}$. The "distance to the apex" indicates the distance along the arches shown in the insets. orientations of complex shapes after draping. It seems that a more refined model, like a mixed kinematic-shear energy model or a finite element model may tackle the problem - this will be a subject of our future work.

\section{Conclusions}

Full-field strain measurements should be routinely used during shear and tension tests of textile reinforcements for: (1) validation of the test procedure by assessing homogeneity of the sample deformation; (2) adequate determination of the strains (shear angle, tensile strain) of the sample, which may differ from the strains imposed by the movement of the testing apparatus.

Optical registration of a grid drawn over the textile with subsequent image analysis can also provide characterisation of the actual deformed state of the sample. However, it may be difficult to make a good grid for textiles with "bumpy" surface. Full-field measurement equipment is easy to use, does not ask for the sample preparation, and produces automatically full characterisation of the strain field.

Meso- and micro-observations of strains in the fabrics on the scale level of the unit cell provide insight into the fabric behaviour during deformation, revealing the mechanisms of the yarn interaction.

Full-field measurements of the local deformations on a composite part after forming provide a convenient tool for the determination of the local fibre orientations and shear angles over the part and for assessing the validity of drape predictions by forming simulation software.

\section{Acknowledgements}

The work reported here has been carried out in K.U. Leuven: in the scope of the projects G.0534.04 and G.0233.07 funded by FWO (Flanders), ITOOL (European Commission) and "Predictive tools for permeability, mechanical and electro-magnetic properties of fibrous assemblies" (IWT, Flanders); in Lyon: in the scope of the projects ITOOL (European Commission), MACODEV (Rhone-Alpes region).

\section{References}

[1] Hearle JWS, Amirbayat J, Twaites JJ, editors. Mechanics of flexible fibre assemblies. Alphen aan den Rijn: Sijthoff and Nordhof; 1980.

[2] Long AC, editor. Design and manufacture of textile composites. Cambridge: Woodhead Publishing Ltd.; 2005.

[3] Boisse P, editor. Composite forming simulations. Eur J Comput Mech 2005;14 [special issue].

[4] Long A, editor. Composite forming technologies. Cambridge: Woodhead publishing; 2007.

[5] Boisse P, Akkerman R, Cao J, Chen J, Lomov SV, Long A. Composites forming. In: Chinesta F, Cueto E, editors. Advances in material forming. Esaform 10 years. Springer; 2007. p. 61-79.

[6] Boisse P, Buet K, Gasser A, Launay J. Meso/macro-mechanical behaviour of textile reinforcements for thin composites. Compos Sci Technol 2001;61:395-401. 
[7] Boisse P, Gasser A, Hivet G. Analyses of fabric tensile behaviour: determination of the biaxial tension-strain surfaces and their use in forming simulations. Composites Part A 2001;32(10):1395-414.

[8] Lomov SV, Truong Chi T, Verpoest I, Peeters T, Roose V, Boisse $\mathrm{P}$, et al. Mathematical modelling of internal geometry and deformability of woven preforms. Int J Forming Process 2003;6(3-4): 413-42.

[9] Lomov SV, Verpoest I. Model of shear of woven fabric and parametric description of shear resistance of glass woven reinforcements. Compos Sci Technol 2006;66:919-33.

[10] Zouari B, Dumont F, Daniel JL, Boisse P. Analyses of woven fabric shearing by optical method and implementation in a finite element program. In: Proceedings of the sixth ESAFORM conference on material forming, Salerno; 2003. p. 875-87.

[11] Daniel JL, Soulat D, Boisse P. Shear and tension stiffness influence in composites forming modelling. In: Proceedings ESAFORM-2004, Trondheim; 2004. p. 301-4.

[12] Hivet G, Dumont F, Launay J, Maurel V, Vacher P, Boisse P. Optical analysis of woven fabric's shear behaviour. In: Proceedings ESAFORM-2004, Trondheim; 2004. p. 353-6.

[13] Hivet G, Boisse P. Consistent 3D geometrical model of fabric elementary cell. Application to a meshing preprocessor for 3D finite element analysis. Finite Elem Anal Des 2005;42:25-49.

[14] Zouari B, Daniel JL, Boisse P. A woven reinforcement forming simulation method. Influence of the shear stiffness. Comput Struct 2006;84(5-6):351-63.

[15] Boisse P, Zouari B, Gasser A. A mesoscopic approach for the simulation of woven fibre composite forming. Compos Sci Technol 2005;65:429-36.

[16] Lomov SV, Willems A, Verpoest I, Zhu Y, Barburski M, Stoilova T. Picture frame of woven fabrics with a full-field strain registration. Text Res J 2006;76(3):243-52.

[17] Willems A, Vanderpitte D, Lomov SV, Verpoest I. Biaxial tensile tests on a woven glass/PP fabric under optical strain measurement In: Procedings of the eighth ESAFORM conference on material forming, Cluj-Napoca; 2005. p. 1007-10.

[18] Lomov SV, Willems A, Barburski M, Stoilova T, Verpoest I Strain field in the picture frame test: large and small scale optical measurements. In: Procedings of the eighth ESAFORM conference on material forming, Cluj-Napoca; 2005. p. 935-8.

[19] Willems A, Lomov SV, Yingbo Z, Verpoest I, Vandepitte D. Deformability characterisation of fabrics using large and small scale full field optical strain measurements. In: Proceedings of the European conference on composite materials (ECCM-12), 29th August-1st September, Biarritz; 2006 [CD edition].

[20] Prodromou AG, Chen J. On the relationship between shear angle and wrinkling of textile composite preform. Composites Part A 1997;28:491-503.

[21] Potluri P, Perez Ciurezu DA, Ramgulam RB. Measurement of mesoscale shear deformations for modelling textile composites. Composites Part A 2006;37(6):303-14.

[22] Zhu B, Yu TX, Tao XM. Large deformation and slippage mechanism of plain woven composite in bias extension. Composites Part A 2007;38:1821-8.

[23] Lomov SV, Barburski M, Stoilova T, Verpoest I, Akkerman R, Loendersloot $\mathrm{R}$, et al. Carbon composites based on multiaxial multiply stitched preforms. Part 3: Biaxial tension, picture frame and compression tests of the performs. Composites Part A 2005;36:1188-206.

[24] Launay J, Lahmar F, Boisse P, Vacher P. Strain measurement in tests on fibre fabric by image correlation method. Adv Compos Lett 2002;11(1):7-12.

[25] Dumont F, Hivet G, Rotinat R, Launay J, Boisse P, Vacher P. Mesures de champs pour des essais de cisaillement sur renforts tisses. Mech Ind 2003:4:627-35.
[26] Rethore J, Gravouil A, Morestin F, Combescure A. Estimation of mixed-mode stress intensity factors using digital image correlation and an interaction integral. Int J Fract 2005;132:65-79.

[27] Touchal S, Morestin F, Brunet M. Various experimental applications of digital image correlation method. In: Proceedings of CMEM 97 (computational methods and experiental measurements VIII), Rhodes; 1997. p. 45-58.

[28] Long A. Process modelling for textile composites. In: International conference on virtual prototiping EUROPAM 2000, Nantes; 2000. p. $1-17$.

[29] Long AC, Clifford MJ, Harrison P, Rudd CD. Modelling of draping and deformation for textile composites. In: ICMAC - international conference for manufacturing of advanced composites. Belfast: IOM Communications; 2001. p. 66-76.

[30] Mohammed U, Lekakou C, Dong L, Bader MG. Shear deformation and micromechanics of woven fabrics. Composites Part A 2000;31:299-308.

[31] Nguyen M, Herszberg I, Paton R. The shear properties of woven carbon fabrics. Compos Struct 1999;47:767-79.

[32] Sharma SB, Sutcliffe MPF, Chang SH. Characterisation of material properties for draping of dry woven composite material. Composites Part A 2003;34:1167-75.

[33] Peng XQ, Cao J. A contimuum mechanics-based non-orthogonal constitutive model for woven composite fabrics. Composites Part A 2005;36:859-74.

[34] Peng XQ, Cao J, Chen J, Xue P, Lussier DS, Liu L. Experimental and numerical analysis on normalisation of picture frame tests for composite materials. Compos Sci Technol 2004;64(1):11-21.

[35] Wang J, Page JR, Paton R. Experimental investigation of the draping properties of reinforcement fabrics. Compos Sci Technol 1998;58:229-37.

[36] Potter K, Bias D. extension measurements on cross-plied unidirectional prepreg. Composites Part A 2002;33:63-73.

[37] Lebrun G, Bureau MN, Denault J. Evaluation of bias extension and picture frame test methods for the measurement of intraply shear properties of $\mathrm{PP} /$ glass commingled fabrics. Compos Struct 2003;61:341-52.

[38] Cao J, Cheng HS, Yu TX, Zhu B, Tao XM, Lomov SV, et al. A cooperative benchmark effort on testing of woven composites. In: Proceedings of the seventh Esaform conference on material forming, Trondheim, Norway; 2004. p. 305-8.

[39] Harrison P, Clifford MJ, Long AC. Shear characterisation of viscous woven textile composites: a comparison between picture frame and bias extension experiments. Compos Sci Technol 2004;64:1453-65.

[40] Gasser A, Boisse P, Hanklar S. Analysis of the mechanical behaviour of dry fabric reinforcements. 3D simulations versus biaxial tests. Comput Mater Sci 2000;17:7-20.

[41] Harrison P, Wiggers J, Long AC, Rudd CD, Constitutive modelling based on meso and micro kinematics for woven and stitched fabrics. In: Proceedings ICCM-14, San Diego; 2003 [CD edition].

[42] Manthey DW, Lee D. Recent developments in a vision-based surface strain-measurement system. J Miner Met Mater Soc 1995;47:46-9.

[43] Long A, Rudd CD. Characterizing the processing and performance of aligned reinforcements during perform manufacture. Composites Part A 1996;27:247-53.

[44] Nino GF, Bersee HEN. Internal behaviour of intraply shear in thermoformed composites. In: Proceedings of the eighth international conference on textile composites (TEXCOMP-8), Nottingham; 2006 [CD edition]

[45] Vanclooster K, Lomov SV, Willems A, Verpoest I. Measurement of local deformations on thermoformed composite parts under different process conditions. In: Proceedings of the 10th ESAFORM conference. Zaragoza: American Institute of Physics; 2007. p. 1058-63.

[46] Willems A, Lomov SV, Vandepitte D, Verpoest I. Double dome forming simulations of woven textile composites. In: Juster N, Rosochowski A, editors. The nineth international conference on material forming ESAFORM, April 26-28, 2006, Glasgow; 2006. p. 747-50. 